\title{
Esofagitis eosinofilica: a propósito de un caso
}

\author{
AE. Ballón Hurtado a, A. Encinas Bascones ${ }^{b}$, MA. Bascones Martínez ${ }^{c}$ \\ ${ }^{a}$ MIR-Medicina de Familia. ${ }^{b}$ Médico. Pediatra. \\ CS Estrecho de Corea. Servicio Madrileño de Salud, Área 4. Madrid. España.
}

Rev Pediatr Aten Primaria. 2009; I : 625-30

Amparo Elizabeth Ballón Hurtado, amparobahu@hotmail.com

\begin{abstract}
Resumen
La esofagitis eosinofilica es una enfermedad inusual y emergente en los últimos años que se caracteriza por un infiltrado de más de 20 eosinófilos por campo de gran aumento en la biopsia del tejido esofágico. Se describe en todas las edades aunque aparentemente es más frecuente en niños. La etiología no está clara pero se sugiere que la atopia o las alergias juegan un rol importante en el desarrollo de la enfermedad. La presentación clínica es variada: la disfagia y la impactación alimentaria son las más frecuentes. No existe un tratamiento específico. Los corticoides tópicos deglutidos son los fármacos de elección, pero en niños con alergia alimentaria el tratamiento se basa en dietas de exclusión. Presentamos el caso clínico de un niño de 12 años con antecedente de dermatitis atópica y alergia que es hospitalizado por presentar un cuadro de melena con urticaria aguda. A su vez, se hace una breve revisión del diagnóstico y el tratamiento de esta patología.
\end{abstract}

Palabras claves: Esofagitis, Eosinofilia, Hipersensibilidad.

\section{Abstract}

Eosinophilic esophagitis is an unusual and emerging disease in the last years that is recognized by the presence of more than 20 eosinophils per high-powered field on esophageal tissue biopsy. It is described in all ages although apparently is more frequent in children. It is suggested that atopy or allergic mechanisms play an important role in the development of this disease but the etiology is not clear yet. The more frequent symptoms are dysphagia and food impaction among the varied clinical manifestations. No specific treatments exist but topical swallowed steroids are the first choice although an exclusion diet is preferred in children with food allergy. We report the case of a 12-year-old child, suffering from atopic dermatitis and other allergies, admitted to hospital for an episode of melena and urticaria and discuss the diagnosis and the treatment of this pathology.

Key words: Esophagitis, Eosinophilia, Hypersensitivity.

Los autores declaran no presentar conflictos de intereses en relación con la preparación y publicación de este artículo. 


\section{Introducción}

La esofagitis eosinofílica (EEo) es una enfermedad inflamatoria crónica caracterizada por la infiltración eosinofílica de la mucosa del esófago. Fue denominada en los años setenta con diversos términos. El primer caso de inflamación eosinofílica fue descrito por Dobbins en 1977; sin embargo, hasta 1993 la EEo no fue definida como una patología clínicamente diferente del resto de las enfermedades eosinofílicas del tracto gastrointestinal'. A pesar de existir pocos datos epidemiológicos de la prevalencia y la incidencia de la EEo, el número de casos diagnosticados se ha incrementado en los últimos años, probablemente por la mejora en el conocimiento de la enfermedad. La EEo se da preferentemente en el sexo masculino (3:1). La edad promedio de desarrollo en niños se encuentra entre los 7 y los 10 años, y en adultos, entre los 30 y los 40 años. La fisiopatología no está del todo clara; sin embargo, hay una amplia bibliografía que sustenta la EEo como una alteración inmunoalérgica, posiblemente causada por alérgenos alimentarios. La clínica varía según el grupo etario, desde dolor abdominal y torácico recurrente, vómitos, disfagia, impactación alimentaria y pirosis, hasta retraso del crecimiento y síntomas de reflujo gastroesofágico re- fractarios al tratamiento con inhibidores de la bomba de protones. Recogemos el caso clínico de un paciente pediátrico con urticaria y melena aguda, síntoma raro de presentación de una EEO.

\section{Caso clínico}

Paciente varón de 12 años de edad nacido de embarazo y parto normales, período neonatal normal, lactancia materna durante 10 meses, desarrollo psicomotor normal, desarrollo somático ascendente, inmunizaciones según el calendario, alimentación actual variada, trastorno por déficit de atención con hiperactividad desde los 9 años en tratamiento con metilfenidato, sensibilizado a epitelio de animales y con rinoconjuntivitis estacional. En algunas ocasiones ha presentado lesiones de urticaria sin poder establecer relación con ningún desencadenante. Dermatitis atópica en la primera infancia. Madre de 43 años y padre de 45, sanos.

En septiembre de 2007 ingresa en urgencias por un cuadro de melenas tras la ingesta de boquerones en vinagre 4 horas antes. El cuadro comenzó con melenas, así como con la aparición de una urticaria generalizada predominante en hombros y abdomen. Previamente el paciente refería dolor leve en el epigastrio. 


\section{Exploración física}

Temperatura: $37,1{ }^{\circ} \mathrm{C}$, peso: $35 \mathrm{~kg}$, buen estado general, bien hidratado, buena coloración de la piel y las mucosas. No presenta exantemas ni petequias, ni tampoco adenopatías significativas. Lesiones habonosas en el abdomen y los miembros superiores. Exploraciones pulmonar y cardiovascular normales. Abdomen blando y depresible, sin masas ni visceromegalias palpables; no se produce dolor en la palpación; ruidos hidroaéreos conservados. Tacto rectal: dedil manchado, heces negras. Otorrinolaringología: oídos y faringe de aspecto normal. Neurológico: colaborador, consciente y orientado, no presenta rigidez de nuca ni signos meníngeos, marcha normal y pupilas isocóricas y normorreactivas.

\section{Exámenes complementarios}

1) Bioquímica: todos los parámetros se encuentran dentro de la normalidad, incluida la ferritina y los anticuerpos de celíaca.

2) Hemograma: hematíes: $5.180 .000 /$ $\mathrm{ml}$; hemoglobina: 14,7 g/dl; hematocrito: 44; volumen corpuscular medio: $84 \mathrm{fl}$; hemoglobina corpuscular media: 28; plaquetas: $342.000 / \mathrm{ml}$; leucocitos: $7.900 / \mathrm{ml}$ (fórmula: N 38; L 40; M 7,2; E 13,9; eosinófilos totales: 1.100).

3) Coagulación normal.
4) Hemorragias ocultas en heces: positiva.

5) IgE total: $1.095 \mathrm{KU} / \mathrm{l}$. IgE específica mediante CAP (IgEEmCAP) frente a caspa de caballo: 52,5 KU/l; IgEEmCAP frente a boquerón: clase cero; anisakis: 6,33 KU/l; almendra: 0,43 KU/l; pipa de girasol: 0,65 KU/l; nuez de nogal: 0,89 $\mathrm{KU} / \mathrm{l}$.

6) Complementos $\mathrm{CH} 50, \mathrm{C} 3$ y $\mathrm{C} 4$ : normales.

7) Pruebas cutáneas frente a inhalantes habituales: positivas para pólenes de gramíneas, olea, arizónica, plátano de sombra, malezas, epitelio de perro y gato; en el límite de la positividad para hongos, y negativas para ácaros del polvo doméstico. Test cutáneos para batería de alimentos negativos para leche de vaca y huevo; en el límite de la positividad para mezcla de pescado azul y mezcla de pescado blanco; positivo para mezcla de frutos secos y anisakis, y negativo para las lentejas. Pruebas epicutáneas con alimentos negativas para leche y fracciones, pescado blanco, azul, frutos secos, lentejas, trigo, epitelio de perro y gato, ternera, pollo, emperador, bacalao, merluza, atún, gallo y anisakis.

8) Panendoscopia oral. Esófago: acantosis glicógena, erosiones superficiales de 2-3 cm de longitud, imágenes redondeadas, pequeñas, blancas, en acúmulos 
en tercios medio e inferior. Cardias normal, estómago, cuerpo y antro normales. Biopsia: mucosa duodenal sin lesiones, mucosa astral sin lesiones, mucosa esofágica con lesiones características de esofagitis eosinofílica algo más intensa en el esófago medio y superior.

9) Ecografia abdominal normal.

\section{Discusión}

La EEo es una patología poco frecuente caracterizada por la inflamación con infiltrado eosinofílico del esófago sin reflujo gastroesofágico². Se ha descrito en niños $s^{3,4}$ y adultos, aunque aparentemente es más prevalente en los primeros; en éstos, a diferencia de los adultos, se observan eosinofilia periférica y antecedentes de alergia. La fisiopatología aún no está completamente establecida. Existen varias teorías que relacionan factores endógenos y ambientales. Basándose en los resultados de diversos estudios, se observaron dos tipos de mecanismos: uno dependiente de IgE, o extrínseco, en relación con la predisposición atópica, los elevados valores séricos de lgE y el alto porcentaje de pacientes positivos para los test intradérmicos de sensibilidad; $y$ otro, independiente de IgE, o intrínseco, en asociación con un porcentaje elevado de pacientes con pruebas epicutáneas positivas no dependientes de lgE, en los cuales se cree que los linfocitos $T$ juegan un papel fundamental.

Las pruebas cutáneas de sensibilidad para alimentos y para neumoalérgenos ayudan a identificar los alérgenos y el estado atópico de los pacientes con EEO. El mecanismo inmunoalérgico puede desencadenarse en el esófago, en los bronquios o incluso en la piel. Varios estudios relacionan el papel de los linfocitos $T$ helper tipo 2 y las citocinas Th2 (como IL-4, IL-5 e IL-13) con el reclutamiento y la desgranulación de los eosinófilos que producen el daño del epitelio escamoso. Se han observado concentraciones de eotaxin-3 incrementadas en la EEo en diversos estudios. En un futuro, la expresión de eotaxin-3 y su variación genética pueden ser marcadores prometedores para distinguir la EEo de otras causas de esofagitis ${ }^{5}$. Las manifestaciones clínicas más frecuentes varían según el grupo etario. En niños se pueden presentar como dolor abdominal y torácico recurrente, vómitos, retraso del crecimiento y sensación de ascenso del alimento ${ }^{3,4,6}$. En adultos, los síntomas principales son la disfagia intermitente y las impactaciones alimentarias ${ }^{5}$.

Los hallazgos endoscópicos más comunes son: surcos esofágicos lineales, anillos esofágicos, granulado blanquecino y estenosis esofágica. Las placas 
blanquecinas están asociadas con el hallazgo de microabscesos eosinofílicos y áreas de gran densidad de infiltrado eosinofílico ${ }^{3,4,6,8}$.

El diagnóstico de la EEo debe sospecharse a partir de las características clínicas y los hallazgos endoscópicos. Sin embargo, la confirmación definitiva debe ser anatomopatológica; la presencia de más de 20 eosinófilos por campo de gran aumento es el criterio diagnóstico definitivo.

Se debe establecer el diagnóstico diferencial con la enfermedad por reflujo gastroesofágico, debido a que también aumenta el número de eosinófilos esofágicos; sin embargo, el incremento nunca es mayor de 10 eosinófilos por campo de gran aumento. Dicho incremento se produce fundamentalmente en el tercio esofágico distal 5 .

Actualmente no existe un tratamiento definitivo para la EEo. En niños es electiva la restricción dietética: se realizan dietas de exclusión de los alimentos cuyo resultado fue positivo para los test cutáneos de alergia, o dieta de exclusión de los alimentos alergénicos más frecuentes (leche, huevo, soja, trigo, frutos secos o mariscos), con la posterior reintroducción progresiva de cada alimento hasta encontrar el que desencadena la clínica. También se puede recurrir al uso de fórmulas elementales basadas en aminoácidos ${ }^{4,5}$. En algunos estudios se han empleado los corticoides tópicos, como el propionato de fluticasona en dosis de $220 \mathrm{mcg}$ (2-4 puff deglutidos cada 12 horas) durante 4-6 semanas. Los corticoides sistémicos como la metilprednisolona en dosis de 0,5-1 mg/kg/día (máximo $60 \mathrm{mg} /$ día) durante 6 meses seguidos con una pauta descendente progresiva son una alternativa ${ }^{4,9}$. Los pacientes que presentan lesiones estenóticas van a requerir dilataciones esofágicas endoscópicas. Otras terapias médicas incluyen el uso de montelukast, con el que se observa una mejoría de los síntomas pero no de la histología, además de producirse una recaída precoz tras su suspensión $n^{5,9}$.

En casos refractarios a los tratamientos anteriores se han realizado estudios con mepolizumab, un agente biológico anti-IL-5, que se administra en 3 infusiones mensuales de $10 \mathrm{mg} / \mathrm{kg}$ (máximo $750 \mathrm{mg}$ ). 


\section{Bibliografía}

1. Attwood SE, Smyrk TC, Demeester TR, Jones JB. Esophageal eosinophilia with dysphagia. A distinct clinicopathologic syndrome. Dig Dis Sci. 1993;38:109-16.

2. Ferré-Ybarz L, Nevot Falcó S, Plaza-Martín AM. Eosinophilic esophagitis: clinical manifestations and treatment options. The role of the allergologist. Allergol et Immunopathol. 2008; 36:35865.

3. Orenstein SR, Shalaby TM, Finch R, Pfuetzer $\mathrm{RH}$, DeVandry S, Chensny LJ, et al. The spectrum of pediatric eosinophilic esophagitis beyond infancy: a clinical series of 30 children. Am J Gastroenterol. 2000;95:1422-30.

4. Assa'ad AH, Putnam PE, Collins MH, Akers $\mathrm{RM}$, Jameson SC, Kirby $\mathrm{CL}$, et al. Pediatric patients with eosinophilic esophagitis: an 8- year follow-up. J Allergy Clin Immunol. 2007;119: 731-8.

5. Futura GT, Liacouras CA, Collins MH, Gupta SK, Justinich $C$, Putnam PE, et al. Eosinophilic
Esophagitis in Children and Adults: a systematic review and consensus recommendations for diagnosis and treatment. Gastroenterol. 2007; 133:134263.

6. Gill $R$, Durst $P$, Rewalt $M$, Elitsur $Y$. Eosinophilic esophagitis disease in children from West Virginia: a review of the last decade (1995-2004). Am J Gastroenterol. 2007;102:2281-5.

7. Sgouros S, Bergele C, Mantides A. Eosinophilic esophagitis in adults: a systematic review. Eur J Gastroenterol Hepatol. 2006:18:211-7.

8. González FG, Torres J, Molina UR, Harris PR. Esofagitis Eosinofílica en niños: Características clínicas y endoscópicas. Rev Med Chile. 2009;137: 666-71.

9. Sha A, Hirano I. Treatment of eosinophilic esophagitis: drugs, diet, or dilatacion? Curr Gastroenterol Rep. 2007;9:181-8.

10. Stein ML, Collins MH, Villanueva JM, Kusher JP, Putnam PE, Buckmeier BK, et al. Anti-IL-5 (mepolizumab) therapy for eosinophilic esophagitis. J Allergy Clin Inmunol. 2006;118:1312-9. 